\title{
Research into practice: Virtual exchange in language teaching and learning
}

\author{
Melinda Dooly ${ }^{1 \star}$ (D) and Margarita Vinagre ${ }^{2}$ \\ ${ }^{1}$ Universitat Autònoma de Barcelona, Barcelona, Spain and ${ }^{2}$ Universidad Autónoma de Madrid, Madrid, Spain \\ *Corresponding author: Email: melindaann.dooly@uab.cat
}

\begin{abstract}
In this article, the authors reflect on the ways research on Virtual Exchange (VE) has had an impact on language education practices and, conversely, areas in which research has been underexplored, misapplied or perhaps even over applied by VE practitioners in formal education settings. Starting from a brief historical overview of VE, the text first outlines the features widely accepted as key aspects of this pedagogical approach before considering to what extent research results can be identified in VE implementation. Principal topics covered are the main aims regarding language development when VE is applied, assessment of language development through VE and VE and intercultural competence. While the article is not intended as a comprehensive review, it provides insight into the main foci of VE research and how these findings are reaching the language classroom (primary, secondary and university).
\end{abstract}

\section{Introduction: What is virtual exchange?}

As practitioners and researchers of Virtual Exchange (VE), our remit for this article was to 'think aloud' and provide our personal view of how past and current Second Language Acquisition (SLA) research has been or is being successfully translated into VE-inspired teaching practices. We were asked to consider how research has a bearing on VE in education and conversely which research has not been well applied or is underexplored, misapplied or perhaps even over applied. We begin by explaining why we take the perspective that VE can be considered a pedagogical approach. Firstly, it is based on the number of publications, professional conferences and dedicated foundations and digital platforms now available to the education community that refer to VE, quite often presented as an approach to teaching languages (Dooly \& O’Dowd, 2018; Godwin-Jones, 2019). Following Kumaravadivelu (2006) and Thornbury (2013), both of whom point out that teaching 'methods' cannot be seen as 'unproblematic', we use the term to refer to the ways in which teachers adjust their teaching through 'methodological persuasions', resulting in an 'approach that accords uniquely with their "sense of plausibility"' (Thornbury, 2013, p. 193).

Given the predominance the Communicative Approach (CA) has in the theoretical framing of many publications on VE, we have focused our attention principally on aspects of CA in VE research and practice. However, it must be acknowledged that these categories are by no means clear-cut nor is it possible for us to be aware of all the research that is available - in particular, in languages that we are unfamiliar with. Thus, in our 'thinking aloud', we endeavour to provide some insight into the ways in which VE has had an innovative impact on language teaching and learning - or failed to do so while recognizing that there are many studies available that we have not covered.

Before discussing our views, we provide a brief historical overview of VE and its emergence as an alternative communicative language teaching approach. One of the first challenges for any reflection on VE, which has a relatively short lifespan as an education programme, is to select one terminology

(c) The Author(s), 2021. Published by Cambridge University Press. This is an Open Access article, distributed under the terms of the Creative Commons Attribution licence (http://creativecommons.org/licenses/by/4.0/), which permits unrestricted re-use, distribution, and reproduction in any medium, provided the original work is properly cited. 
and definition (it should be noted that first publications with significant impact began in the early 1990s). VE, Telecollaboration, eTandem or Teletandem, and Collaborative Online International Learning (COIL) are some of the more well-known terms that have been used, often interchangeably, to refer to the process of communicating and collaboratively learning with peers from different locations through the use of technology. Admittedly these terms are not considered by everyone to be synonyms and each term has emerged from different epistemologies and contexts. Moreover, the terms, if seen differently (some researchers do claim they are synonymous) are not mutually exclusive, and arguments regarding differences in terminology are often linked to an individual's dynamics and background references.

So, for a more contemporaneous understanding of VE, a brief historical overview is useful. VE has gained prominence as educators have begun to take advantage of significant advances in and better accessibility to communication technology. In 1995, Warschauer referred to technology-enhanced exchanges as 'virtual connections'. In 2003, Belz used the term 'telecollaboration' to describe this learning context: ' . . internationally dispersed learners in parallel language classes use Internet communication tools such as email, synchronous chat, threaded discussion, and MOOs $^{1}$ (as well as other forms of electronically mediated communication), in order to support social interaction, dialogue, debate, and intercultural exchange' (p. 2).

Seven years later, Lamy and Goodfellow (2010) underscored the difficulties of defining telecollaboration due to the wide range of pedagogical underpinnings that can be found in publications using this term. Indeed, seeming simplicity at times can be Gordian.

Etymologically speaking, telecollaboration can be defined simply as 'collaboration' coupled with the Greek prefix 'tele,' which means distance (...). Thus, we have collaboration at a distance. [But this] is far too facile to encompass the complexities of the underlying learning principles and the activities involved in educational telecollaborative endeavors. (Dooly, 2017, p. 169)

As the practice of using the Internet to connect learners has gained ground (usually through computers but increasingly with hand-held devices such as mobile phones or even gaming devices), other terms have been applied: 'eTandem ${ }^{2}$ or Teletandem' (Telles, 2009; Vinagre \& Muñoz, 2011), 'globally networked learning' (Starke-Meyerring \& Wilson, 2008) or 'online interaction and exchange or OIE' (Dooly \& O’Dowd, 2012).

In parallel to the growing use of communication technology for connecting language learners, there has been a movement to consolidate the pedagogical foundations for this type of exchange and to establish VE as a pedagogical approach (Vinagre, 2017; O'Dowd, Sauro, \& Spector-Cohen, 2019; Dooly \& Masats, 2020; Vinagre \& Oskoz, 2020). O’Dowd (2018a) has argued that two of the most commonly used terms, VE and telecollaboration, are applicable to the same 'pedagogically-structured online collaborative learning initiatives' (p. 2), while in the same article recognizing that 'over the past three decades, approaches to virtual exchange have evolved in different contexts and different areas of education and these approaches have happened, to a great extent, in blissful isolation of one another' (p. 2).

Finally, political forces cannot be ignored when considering which term eventually emerges foremost in mainstream discourse (Ku, 2000; Habermas, 1962[2011]). In 2015, the European Union Education Ministers' Paris Declaration announced imminent and substantial funding would be forthcoming for VE initiatives in education. These funded VE proposals should aim to 'promote citizenship' and 'the values of freedom, tolerance and non-discrimination' as well as prevention of 'extreme radicalism'. That same year, in the USA, the Stevens Initiative was established to promote VE as an international effort to build 'global competence' and 'career readiness 'amongst youth around the world.

Thus, VE is 'the term being increasingly used by foundations, governmental bodies and inter-governmental bodies' (Dooly \& O'Dowd, 2018, p. 15). Even if one does have issues with the implicit underlying agendas of these institutions (Kramsch, 2013), VE appears to be set as the most recognizable term, at least in the EU and the USA. In South America, VE is mostly encountered in 
tandem learning format (a partnership with different mother tongues, aimed at learning the language and culture) and therefore, teletandem is a more predominant term.

Similarly, just as there has been different opinions about the most applicable term, there have also been many proposed definitions. For the sake of brevity, we describe it as a pedagogical approach, supported through the affordances of digital communication tools (e.g. cell phones, tablets, computers), which aims to implement the language teaching principles outlined in CA. In VE, work may be carried out synchronously, which is a growing trend as teachers and students become more familiar with the use of communication software such as Skype, Google Meet or Zoom, although VE may also be done asynchronously through shared authoring tools such as documents, blogs or forums. Although a combination of both formats seems to be ideal, an asynchronous format is often preferred when there are difficulties in finding times and dates that coincide in scheduling or when technological infrastructures are less reliable.

Here are some key features of VE: (1) It is a highly flexible practice that can be incorporated into one's teaching in a variety of manners (in-class or hybrid learning environments); (2) It is generally envisioned as an ideal opportunity to engage students in social interaction and collaboration with other participants whom they would be less likely to meet in 'normal' educational circumstances; (3) it has been considered an alternative to physical mobility for students with disabilities or economic difficulties as well as facilitating inclusion, language practice and internationalization for all; (4) Some VE may include use of self-directed online language learning platforms (e.g. Busuu, Italki) as part of a wider array of planned learning activities (as part of guided language learning that takes place in instructed formal settings with partner teachers). However, VE is different from self-guided learning, as will be explained in more detail in the following sections.

A significant difference of VE from other forms of CA teaching is that it is supported through the connection of language TEACHERS and LEARNERS in different geographical locations and requires carefully designed tasks and activities that must be COllaboratively designed and implemented between more than one teacher. We highlight teachers, learning and collaboration because, recently, digital learning environments and communication technology have leapt into the forefront of educational news as the Covid 19 global pandemic has forced teachers and learners around the world to rapidly shift to online configurations. However, online teaching is not the same as VE. VE involves a mutually supportive, guided learning process between class partners (including teachers); it is not a one teacher per class set up.

\section{Communication as a basis for VE in language teaching}

VE can be seen as originating from the CA in language teaching (Brammerts, 1996; Johnson, 1996; Kern, 1996; Kinginger, 1998; Kinginger, Gourvès-Hayward, \& Simpson, 1999; Müller-Hartmann, 2006; Dooly, 2010, 2017; Kurek \& Müller-Hartmann, 2017; Vinagre, 2017). It is not within the scope of this article to provide more than a broad description of CA, however it is important to understand the impact this approach has had on language teaching in the past 50 years as well as on the development of VE in language teaching and learning. This approach, albeit still loosely defined and often debated, is one of the most widely acknowledged pedagogical frameworks for language material design, class planning, language assessment, teacher education and even curriculum policies in many EU countries. As Thornbury (2013, p. 188) explains:

The 'big idea' that fuelled the communicative approach ( ... ) was Hymes' (1972) notion of communicative competence - the knowledge 'when to speak, when not, and as to what to talk about with whom, when, where in what manner' ( ... ) encouraging course designers to specify learning objectives - and to assess their achievement - in terms of language use.

Drawing on Brown's (2007) list of key features underpinning CA, we underscore the following attributes that are specifically related to VE: (1) a focus on the components of communicative 
competences: functional, sociolinguistic, grammatical, discourse and strategic; (2) an emphasis on authentic and meaningful language use that also heeds the relevance of language forms; (3) a perspective of fluency and accuracy as complementary, not mutually exclusive; (4) priority on language learning tasks that prepare language learners with the communication competences they need outside the classroom; (5) an aim to develop autonomous language learners; (6) a reconceptualization of the teacher-fronted classroom; and (7) prominence of cooperative and collaborative learning. All of these traits contribute to core postulates of VE in language teaching and learning. In particular the use of technology to connect learners across the globe has helped validate the increase of VE to promote meaningful language use; pushing the boundaries of 'classroom tasks' by providing justification for communication between learners outside the class and thereby ensuring more opportunities for learners to focus on language forms as they use the target language, develop their fluency and accuracy and encounter genuine reasons for developing different communicative competences.

VE pedagogical design also has much in common with other communication-based approaches to language teaching, primarily Task-based Language Teaching (TBLT; González-Lloret \& Ortega, 2014), Project-Based Language Teaching (PBLT; Dooly \& Masats, 2020) and Content and Language Integrated Learning (CLIL) or English as a Medium of Instruction (EMI) (Smit \& Dafouz, 2012; Loranc-Paszylk, 2016). In an international survey, it was found that many teachers use TBLT as a main basis for their VE planning (Evaluate Group, 2019); in a large part attributable to language learning that revolves around the completion of meaningful tasks between partners, allowing for spontaneous use of the target language for genuine communication. PBLT has also been increasingly cited as a basis for VE design (Beckett, Slater, \& Mohan, 2020; Thomas \& Yamazaki, 2021 also described as Task-based Projects (TBP)). In VE-based PBLT, the students learn by engaging in personally meaningful projects that are designed to build knowledge and develop skills that have an impact outside of the classroom, while incorporating language learning and intercultural understanding through connections with global learning partners. Similarly, both CLIL and $\mathrm{EMI}^{3}$ are frequently cited as an additional framework for VE (O’Dowd, 2018b). These are methodologies that provide curriculum content in a foreign language which can lead to increased subject knowledge and enhanced L2 proficiency and share with VE their potential to strengthen bilingualism, foster multilingualism and multiculturalism, increase the mobility of citizens and encourage internationalization (Vinagre, 2016a).

Documented examples have described the incorporation of TBLT, PBLL and CLIL/EMI as complementary to the VE design (and at times inextricable from the VE set up), further advancing the argument that VE can help advance CA principles into increasingly innovative pedagogical practices. In the next sections, we look at what research in VE can tell us regarding the expansion of CA principles into VE educational practices. In order to do so, we shall structure the remainder of the article in three sections: (a) research findings that have not been well applied or are underexplored, (b) research findings that have been reasonably well applied and (c) research findings that have been over applied.

\section{Research findings that have not been well applied or are underexplored}

Since one of the main aims of VE entails improving students' foreign language competence and knowledge by connecting learning with other speakers, it comes as little surprise that researching how this aspect is developed has been the focus of multiple studies in specialized literature on VE. Most published studies on VE discuss gains in foreign language and intercultural competence (for syntheses, see Sauro, 2014; Lewis \& O’Dowd, 2016; Avgousti, 2018; Cunningham \& Akiyama, 2018), although there are increasingly more reports on teacher development in VE (O'Dowd, 2018a) along with a small, but growing interest in cross-disciplinary (language and content) VE (Loranc-Paszylk, 2016). Studies on VE in language education have used quantitative, qualitative and mixed method approaches for data analysis; the predominant type of study is a single case (i.e. one exchange; see research review by Cappellini, 2019). When the focus is on language development, many of the studies look principally at the acquisition of lexicon and grammatical structures of the target languages, although some studies have also explored the enhancement of overall language skills and language 
use (speaking, listening, mediation) and the development of fluency and accuracy (Chun, 2015; Cunningham \& Akiyama, 2018). In most of the studies that have been included in this text, the role that VE interaction plays has been described as three-fold since the exchanges can facilitate negotiation of meaning, support focus on form (often through self and peer corrective feedback), and help develop socio-pragmatic competence through target language use.

While many publications have provided valuable insights into how linguistic development takes place in VE, in teaching practice research findings have not always been well applied. This is due to the difficulty of accurately measuring language development longitudinally, an area that remains a challenge for both research and practice. Trying to assess and verify precise learning gains is not always straightforward since 'language competence development is complex and discontinuous and takes place over long periods of time' (Ellis, 2015, p. 297). This is particularly problematic for VE research since most studies describe small scale projects, usually realized over relatively short periods of one to two sessions a week from a month to three months (the usual timespan of one semester; a few VE occasionally last between six months to a year). Even if the VE is reiterated in a programme for years, the students involved change annually. Efforts to address this issue include projects such as Evaluate and Evolve ${ }^{4}$; large scale studies that involve mixed-method approaches to the analysis of both quantitative and qualitative data gathered. However, the lack of longitudinal studies continues to make this aspect difficult to measure rigorously and poses a problem that is difficult to resolve.

Assessment also presents a challenge for pedagogical application of research findings on $\mathrm{VE}$. In particular, there are often misalignments between the type of linguistic skills being developed by the students through VE tasks and how they are being assessed by the teacher. It is not uncommon to read publications of $\mathrm{VE}$ that describe a predominantly oral modality for the learner interaction that is then assessed through a written essay of personal reflection of the experience. Different ways to overcome this shortcoming are to ensure that the (oral) tasks are assessed as part of the students' formative evaluation and, if summative evaluation is also required, that the final exam includes questions that can assess adequately the type of knowledge and skills developed by those tasks. Another potential way forward is to include portfolio-type collection of the ongoing interactions from the $\mathrm{VE}$ as a means of assessing both the process of VE (i.e. students' interaction) and the final learning product (tasks) thereby ensuring that the assessment of the VE fully reflects the students' efforts and what they have learned through the experience. Inevitably, all of the assessment process ties back to the task design for the VE (Hauck, Müller-Hartmann, Rienties, \& Rogaten, 2020).

As regards under-explored research sectors of VE, its application to beginner or younger learners is still lagging behind (Pérez \& Vinagre, 2007; Dooly \& Masats, 2020). Most documentation of VE is in the area of foreign language learning in Higher Education, where the practice has become more widespread. There are far fewer publications by practitioners implementing these exchanges in primary, secondary or vocational education (Dooly \& O'Dowd, 2018). There are many possible causes for the smaller number of examples in primary education, not least of which are presumed constraints of young learners, such as shorter attention span, specific topic interests, less developed communicative competences (in all languages), more rudimentary technological skills, and the need to oversee and limit online engagement with others (Dooly, 2015). Moreover, with very young learners, the usual modality for communication is oral since they may not have sufficiently developed literacy skills for text-based interactions that required reading and writing. Despite these constraints, it is recognized that there are thousands of primary and secondary schools involved in some form of VE. The E-twinning platform ${ }^{5}$ alone has 868,623 teachers and 214,788 schools registered and claims a database of 114,474 projects. Notwithstanding the large numbers, the lack of publications for these age levels remains a key issue; undoubtedly, an underlying reason is that primary and secondary teachers do not engage as frequently in researching and publishing about their experiences as university teachers/researchers do.

Still, it should be noted that there are some published examples of VE projects with very young learners (Bejarano Sánchez \& Giménez Manrique, 2018; García-Martínez \& Gracia-Téllez, 2018; Morcilo Salas, 2018). The commonality of these projects lies in the combination of deliberate 
presentation and practice of potential 'ad hoc' linguistic input, with ample visual aids (e.g. flashcards, mimes and games) before the actual interaction, followed by explicit exercises to heighten language awareness of the target language used during the exchanges. Despite these examples of VE in primary education, there is a need for more research into the transfer to VE of successful strategies for teaching young language learners in-class. For instance, collective story-telling or shared kinaesthetic and affective activities such as shared singing circles have long been bastions of language learning in primary education. These could easily be a backbone of a VE project as they not only activate lexical memory, phonic recitation and practice but through VE, an authentic, engaged audience is ensured (Anguera Cerarols, 2013; Dooly, 2015). As has already been noted, published examples of research into the implementation of VE in primary education remain anecdotal with few funded programmes to examine its impact. This may contribute to a lack of teacher awareness regarding how to design, implement and assess such projects with young beginners.

There is also a paucity in studies on VE in secondary education, although the practice is beginning to gain some ground (Bonet Pueyo, 2018; Bruun, 2018; Ingelsson \& Linder, 2018). A study, based on a systematic review of publications on telecollaborative projects - which compared the typology of tasks described in VE studies carried out with university students with those carried out with secondary students - found that 'studies with secondary school pupils appear to be less interested in tasks with a final, collaborative outcome than those conducted with university students' (Pol, 2013, p. 41). As with primary education, it can be surmised that this is also attributable in some ways to insufficient teacher education in VE regarding how to design VE activities that are meaningful and engaging for the learners.

This same aspect may also be a hindrance for VE in vocational education, especially given the on-going debate regarding the required teaching competence for vocational education (Cedefop, 2017). On the whole, language teaching in vocational education tends to focus on teaching languages for specific purposes, usually with the accent on job-related language skills and quite 'traditionallyfocused' classes (Hernández-Gantes \& Blank, 2009; Poedjiastutie \& Oliver, 2017), with little emphasis on actual use of the target language (Mahbub, 2019). There does not tend to be much institutional cooperation between content vocational teachers and language teachers (Isaksen, 2018), and modest institutional support for innovation. An additional problem appears to be the disconnect between goals and outcomes of VE applied in secondary and vocational education (mainly focused on 'language practice' only) and the learners' needs (language competences that must be assessed for university entrance exams, vocational studies or employment opportunities following graduation).

\section{Research findings that have been reasonably well applied}

One pivotal advantage that can be found in the application of research findings on VE to language learning is that it can help ensure meaningful use of the target language by the learners (Müller-Hartmann, 2006; Chun, 2015; O’Dowd, 2018a). Much research into VE language teaching practices tout positive gains in language learning by foregrounding functional, sociolinguistic, grammatical, discourse, strategic communicative competences and intercultural competences (Dooly \& O’Dowd, 2012; Vinagre, 2016b; Avgousti, 2018; Çiftçi \& Savaş, 2018; Cunningham \& Akiyama, 2018; O’Dowd \& Dooly, 2020). Little (2001), elaborating on the growing role of technology in language education in general and of eTandem in particular, suggested that these practices could hold an essential role in promoting learning autonomy; a point that has been picked up on as a significant area of research in VE (Cappellini, Lewis, \& Rivens Mompean, 2017). Another key area where VE stands out is the opportunity for successfully integrating all components of language learning, as proposed by the Council of Europe (2018); the communication that is required to complete a task, activity or project in VE often requires consolidated deployment of different modalities and communicative competence (Beckett et al., 2020). As Whyte and Gijsen (2016) explain, VE 'offers unique opportunities for purposeful interaction in a communicative context with interlocutors outside the classroom as recommended by second language research' (p. 164). 
Explicitness (e.g. language awareness, focus on form) is another backbone of CA. It must be noted that there has been less research into VE that highlights learners' focus on form (FonF) than more general language gains related to authentic language use. Still, as the field has grown in both practice and research, studies on FonF have also increased. Findings indicate that VE contribute to more explicit FonF by learners (see Ware \& O’Dowd, 2008; Bower \& Kawaguchi, 2011; Vinagre \& Muñoz, 2011; Akiyama, 2014; Li, 2020 for illustrative examples of such studies). VE has been found to be particularly useful for drawing learners' attention to formulaic sequences, communication strategies such as fillers and sociopragmatic features that are common to 'everyday' talk without resorting to contrived role plays or repetitive drills. Still, it is acknowledged that VE is frequently implemented with a rationale of 'more authentic' language practice and far less interrogation of whether it promotes accuracy.

In their review on studies of technology-mediated TBLT, González-Lloret and Ortega (2014) highlight the significance of carefully scaffolded interaction in order to close 'the gap between form-based and function-based learning' (Liang, Xie, \& Gao, 2020, p. 277). Moreover, in order to be successful, much like TBLT or PBL approaches, VE activities must be designed to include these key aspects (Beckett \& Slater, 2018; Dooly \& O’Dowd, 2018; Dooly \& Masats, 2020; Hauck et al., 2020): explicitness (ensuring student focus on how they are learning the language, the competences they are acquiring and the linguistic and non-linguistic communicative features they are using); structure (pedagogical design that fully supports the acquisition and use of the language); and fit (technology tools, language use and didactic expectations that are appropriate to the learners' level). Numerous studies have shown that gains in VE are due to the typology of the task design that was assigned for the language exchange (O'Dowd, 2015; Lewis \& O’Dowd, 2016; Vinagre, 2017; O'Dowd et al., 2019; Hauck et al., 2020). And while studies into FonF predominantly look at adult language learners involved in VE (Cunningham \& Vyatkina, 2012; Cunningham \& Akiyama, 2018), interactional analysis of VE between very young language learners in carefully scaffolded exchanges also indicate language noticing and use of formulaic language and short turn-taking devices (Dooly, 2015). As with older beginning level adults, the pre-task work, the task design and expedient input-based instruction during the exchange were key to ensuring language uptake.

This brings us to the role of the teacher in VE. Many single case studies as well as a few large-scale studies (Fuchs, Snyder, Tung, \& Han, 2017; Evaluate Group, 2019) foreground the multiple challenges faced by teachers when designing and implementing a VE approach. The double-edged sword of VE is that, while it opens up manifold opportunities for the use of the language productively and receptively, these often occur in unrehearsed contexts. VE is a learner-centered and task-oriented practice wherein the traditional teacher's role is no longer predominant. For many teachers and students, this heightened learner responsibility not only produces anxiety (despite the motivation of engaging with others in the target language), but it may also increase a sense of taking part in unfocused activities that seem to lack specific linguistic aims. Hopefully, as with other pedagogical approaches related to CA such as CLIL/EMI or TBLT, VE as a pedagogical approach to language learning will become an integral part of teacher education curricula in the near future so these doubts and worries can be overcome.

\section{Research findings that have been mis- or over applied}

The focus on intercultural learning seems an almost natural extension of the opportunities afforded through the increased contact between language learners from different parts of the world and, together with language development, this is the area where much of the research on VE converges (Ortega, 2017; Çiftçi \& Savaş, 2018; Godwin-Jones, 2019). A recurring aspect mentioned in publications on VE refers to enhanced intercultural communicative competences as a result of sustained communication with speakers of other languages and cultures. However, there have been interrogative voices regarding assumed intercultural gains that occur merely through contact with speakers of other languages (Helm, 2013, 2016; Dooly, 2016; Flowers, Kelsen, \& Cvitkovic, 2019; Godwin-Jones, 2020; O’Dowd \& Dooly, 2020). Below we describe the main gaps we perceive in the research. 
Many studies mention the underlying need for negotiation as a pathway to development of intercultural competences (Avgousti, 2018; Çiftçi \& Savaş, 2018). However the emphasis tends to be on a rather binary, quasi-utilitarian perspective of global communication wherein effective and 'productive' communication is the ultimate aim. In short, in a large number of reports on the outcomes of VE, claims of gains in Intercultural Competence (IC) are recurrently based on abridged notions of Intercultural Communicative Competence (ICC) and/or Intercultural Awareness (IA) that emerge as the learners get to know each other and discuss topics in the foreign language (Train, 2006; Dooly, 2016; Helm, 2016; Godwin-Jones, 2020). Moreover, it seems that the modality itself (communication technology), which serves as the conduit for opening up the classroom, frequently leads the teacher to assume there are intercultural gains simply because the learners are engaging in a language exchange with others outside of their immediate socio-cultural environment. On a positive note, VE research has contributed to raising awareness of the potential for these gains but at the same time it has highlighted shortcomings in the application of the VE pedagogical approach, such as an underapplication of ICC; or at least little that goes beyond the superficial. In part this may be due to related aspects such as teachers' expectations, assumptions and theoretical grounding regarding ICC and IA often lacking profundity in VE teacher training courses.

Many of the studies on VE gloss over the difficulties of measuring intercultural learning and too often minimize the challenges and complexity of identifying and verifying gains in intercultural competence (Bueno-Alastuey \& Kleban, 2016; Godwin-Jones, 2019). The reasons behind this obstacle are many, starting with the fact that there is not one single definition that holds consensus among scholars on interculturality. As Furstenberg (2010) explains, this is inherent to the definition of culture itself which is 'a highly complex, elusive, multi layered notion that encompasses many different and overlapping areas and that inherently defies easy categorization and classification' (p. 329). Likewise, there are a multitude of definitions for intercultural competence. A common denominator underlying almost all definitions of this competence is the capacity to step beyond one's own culture and interact with others from different linguistic and cultural backgrounds.

Taking this notion as their basis, most models of ICC elaborate on the different aspects of (self) awareness and internal transformation required in the process of becoming successful intercultural communicators (see Dooly, 2016 for an overview of definitions related to IC in telecollaboration; based on Spitzberg and Changnon's (2009) synthesis of '300-plus terms and concepts'; see also Vinagre \& Corral, 2019). In relation to this, we have pinpointed this as a gap in VE: the frequent oversimplification of what is entailed in the notion of intercultural awareness and intercultural competence (Train, 2006; Kramsch, 2014; Dooly, 2016; Alonso \& Vinagre, 2017; Godwin-Jones, 2019; Golubeva \& Guntersdorfer, 2020).

Another problematic issue we have detected is the way in which intercultural gains are predominantly assessed in VE (Avgousti, 2018). As already mentioned, gains in the development of intercultural competence are difficult to verify; in particular a key challenge lies in the assessment of the attitudinal component that is inherent to most definitions of IC. Evaluation of attitude is highly complex (De Vellis, 2003) not only in VE but also in face-to-face learning environments. Some VE reports claim to document IC gains by the number of references to 'Big $\mathrm{C}^{\prime 6}$ discoveries in self-reflection. Many other VE practitioners overly rely on self-report methods with a strong emphasis on communication aspects related to negotiation of moments of conflict or episodes of new awareness of similarities or differences between the cultures (again, usually in reference to 'Big C') of the learners involved.

Self-reporting, which is a frequent tool for measuring IC in VE, can also produce out-of-context, short statements that can be misleadingly assumed to represent IC gains. And, of course, there is always the inevitable question of self-censoring that goes along with self-reporting. As Merino and Tileaga (2011) have argued, self-reporting about IC can be a way of showing one's self in a better light as well as simply being an articulation of what others want to hear (e.g. the 'politically correct' answer for the teacher).

Another issue in VE that is a commonplace in IA and IC debates is the recurrent essentialism of culture (O’Dowd \& Dooly, 2020). In the words of Dervin and Gross (2016, p. 3): 'As paradoxical as it 
might seem, an approach to intercultural competence that fails to point coherently, cohesively and consistently to the complexity of self and the other fails to accomplish what it should do: Helping people to see beyond appearances and simplifying discourses - and thus lead to 'realistic' encounters.'

Thus, a key trait of VE that is frequently and positively highlighted - the opportunity for contact with 'realistic encounters' with users of the target language - can potentially lead to entrenched personal stereotypes if not interrogated more critically in the application of the VE approach. Indeed, uninformed use of communication technology has been reported to exacerbate individual prejudices (Avram, Micallef, Patil, \& Menczer, 2020). For language teaching, and in particular, VE, this must be squarely taken on board. Kramsch (2013) stresses the role:

(... ) of a cyberculture that is increasingly shaping both language and culture and transforming social life. As the computer transforms the very time/space axes of our existence and redefines the real, it has generated feelings of empowerment, of liberation from cultural conventions and constraints; it has opened up dreams of connectivity and ubiquity of an a-cultural, a-historical kind. (... ) For language teachers, the question of culture will become more acute: Which culture to teach in a multilingual world of diasporas, forced migrations and global communication technologies? (pp. 312-313).

Moreover, VE teachers are often unprepared for the 'grey' areas that emerge from these 'authentic' exchanges. In particular, teachers will often try to downplay tensions and conflicts that may arise, rather than embracing these moments as opportunities for dialogue and reflection (Helm, 2016; Godwin-Jones, 2019). Basing her framework on Lederach (1995), who argued for legitimizing 'conflict as an agent of change' (p. 19) - as well as work carried out by Phipps and Levine (2010), who asserted that 'language pedagogies [should] rise to the challenges of conflict transformation because conflict transformation occurs in languages' (p. 12) - Helm (2013) proposes a dialogic model for telecollaboration. In this model, tensions between groups or individuals need not be avoided or 'smoothed over'; rather a more dialogic model that embraces 'openness and sincerity' where 'conflict and dissensus' are 'seen as a natural social phenomenon and as a key for learning to take place' (p. 33).

With guided reflection, individual discomfort encountered during these distanced exchanges can 'serve the important function of bringing to awareness each individual's personal boundaries' (McConachy \& Liddicoat, 2016, p. 18) and help push the learners' understanding of the diversity that is composite to individual identities. This may require coping with ambiguity - a disposition that even VE teachers may have difficulties with, let alone their students:

IC can be quite unstable as it is negotiated in interaction with 'complex' people and in specific contexts, which has an impact on power relations. In some situations, because one feels inferior or simply because one is tired, the noble objectives of non-essentialism and non-culturalism cannot be met even if one tries hard. IC should thus recognize their importance but, at the same time urge its supporters to remain aware of the 'simplexity' of any act of interaction. (Dervin \& Gross, 2016, p. 5).

'Simplexity' is a portmanteau made up of 'simple' and 'complexity' that captures the fluid continuum between the two states which humans are enacting and living all the time. This is quite different from the oversimplication of research results, for instance findings that indicate VE can elicit IC gains. The overgeneralization of findings of IC gains in VE may lead the teacher to assume that engagement with others is sufficient, without taking into consideration the 'simplexity' of the VE environment and the need to support IC and IA development.

While the experience of interacting with new collaborative partners may be generally exciting, innovative or motivating, it may also elicit less than positive feelings at times. Frustration due to the amount of effort needed, feelings of inadequacy, worries about lack of technological skills needed for the VE; there are innumerable reasons why students may feel negative about the exchange, which 
can subsequently be transmitted to their partners and interpreted negatively as regards their IC. The assumption by most teachers and students is that VE is inherently motivating (Evaluate Group, 2019, p. 31), but at the same time it can be anxiety-producing - a feature that is far less pronounced in reporting of outcomes of VE. Moreover, when negative reactions are documented, potential causes for these feelings are not usually attributed to or dealt with under the paradigm of IA or IC by VE practitioners; normally they are considered as pedagogical or technological issues.

Finally, research on IC development has been mostly led by content-based analysis of students' contributions and reports. Given that IC includes the knowledge, skills and attitudes speakers need to interact successfully in intercultural situations (Arasaratnam \& Doerfel, 2005; Risager, 2007) it comes as little surprise that studies fall short of providing the full picture especially in regards to the attitudinal component, which is, as discussed above, the most difficult to measure. At the same time, it is arguably the most important given that it conditions the success of intercultural relations (Byram, 1997). The fact that attitudes are so relevant for intercultural learning and at the same time so problematic to assess has led researchers to look for alternative analyses that can provide insights into its development. Recent efforts include applying linguistic approaches such as the systemic-functional Appraisal model (Vinagre \& Corral, 2018; 2019; Cunningham \& Ryshina-Pankova, 2020; Vinagre \& Oskoz, 2020), analysing linguistic items in virtual interaction using software programs such as Linguistic Inquiry and Word Count (LIWC) (Helm \& Baroni, 2020), or using combinations of models such as Gardner and Lambert's (1972) socio-educational model of motivation and attitude, Bennett's (1993) developmental model of intercultural sensitivity and Byram's (1997) model of ICC (Abrams, 2020) to the analysis of VE interaction and tasks. Results from these studies have yet to be transferred to the classroom given that they are very recent. However, findings can be applied to scaffolding VE intercultural communication by ensuring that students prioritize social interaction over task completion and learn to face diversity and conflicts rather than avoiding them.

\section{Conclusions}

VE is a highly flexible pedagogical practice that stems from the CA to language teaching. VE makes optimal use of communication technology to transform and transfer language learning from within classroom boundaries to worldly interactions with other geographically-distanced learners. Key goals of $\mathrm{VE}$ are to engage students in social interaction and collaborative learning with learners whom they would not normally communicate so they can use and reflect on the target language through authentic dialogue. Documentation of VE has escalated in recent years, and studies predominantly show positive results in language learning and gains in intercultural awareness. However, there are also some notable shortcomings in VE research and practice. Assessment of both linguistic and intercultural competences tend to be based on short-term, single case studies, sometimes with only one of the two (or more) partner groups involved in the data compilation. This is compounded by a lack of systemic application of parameters for assessment. Regarding IA and IC, the predominance of self-reporting and the evaluation of the attitudinal component are particularly problematic, along with an over-simplification of IC. This reductivism can lead to claims of development in IC that may be exaggerated in dimension and permanence. Moreover, VE teachers frequently avoid dealing with the tensions or conflicts that may arise during the exchanges, preferring to focus on reflections about awareness of partners' 'Big C' (topical issues) as examples of increased IA or IC.

This brings up a final key area for improvement in VE, teacher education. Teachers need to be introduced to the approach and provided with sufficient training on how to implement VE in their teaching. They need to become familiar with and know how to connect the increasing volume of theoretical and empirical studies to the enhancement of their own practices. Diversity of application is intrinsic to the wide reach that VE has for teaching and learning (literally spanning the entire globe, limited only by access to the necessary technology) and in this respect VE teacher education must be both context-bound and boundless so that practitioners are fully prepared for its implementation. 
Funding. Research was funded by the VELCOME project, granted by the Spanish Ministry of Science and Innovation (RTI2018-094601-B-100). It was also supported by Assess.net, a Marie Curie Fellowship project (H2020-MSCA-IF-2018 845783), funded by the European Commission, Research Executive Agency, Horizon 2020.

\author{
Notes \\ ${ }^{1}$ MOOS are Object-Oriented MUDs (Multiple User Dimensions or Domains). These are virtual places where students can \\ come together to interact and learn. \\ 2 eTandem is a specific model of VE. Tandem learning refers to a partnership in which two people with different mother \\ tongues work together with the purpose of learning each other's native language and learning about each other's character \\ and culture (Little \& Brammerts, 1996, p. 10). \\ 3 Although CLIL and EMI are sometimes used indistinctly, some authors suggest that CLIL describes more accurately bilin- \\ gual education in secondary contexts, while EMI is preferred to refer to non-language content subjects which are taught \\ through English in higher education settings (Smit \& Dafouz, 2012). \\ ${ }^{4}$ Evaluating and Upscaling Telecollaborative Teacher Education (582934-EPP-1-2016-2-ES- EPPKA3-PI-POLICY); \\ Evidence-Validated Online Learning through Virtual Exchange (https://evolve-erasmus.eu/). \\ 5 https://www.etwinning.net/en/pub/index.htm \\ 6 'Big C' and 'Little c' (Kumaravadivelu, 2008) are terms used to describe the highly 'visible' traits often associated with a \\ particular culture (food, clothing, traditions would be 'Big C') and 'little c' commonly refers to more intangible and perhaps \\ regional aspects related to aspects such as social norms or communication characteristics.
}

\title{
References
}

Abrams, S. (2020). Reconsidering attitude as a relational, negotiated sociocognitive construct. In A. Oskoz \& M. Vinagre (Eds.), Understanding attitude in intercultural virtual communication CALICO special volume: Advances in CALL research and practice (pp. 9-29). Sheffield, UK: Equinox.

Akiyama, Y. (2014). Using skype to focus on form in Japanese telecollaboration: Lexical categories as a new task variable. In S. Li \& P. Swanson (Eds.), Engaging language learners through technology integration: Theory, application and outcomes (pp. 181-209). Hershey, PA: IGI Global.

Alonso, I., \& Vinagre, M. (2017). Interculturality and identity in computer-mediated communication: Findings from L2 teaching contexts. CALL (SI), 30(5), 343-350. doi:10.1080/09588221.2017.1321329

Anguera Cerarols, C. (2013). L'ensenyament de l'espai geogràfic en una aula d'anglès de primària. Bellaterra Journal of Teaching \& Learning Language \& Literature, 6(4), 33-53. https://doi.org/10.5565/rev/jtl3.549

Arasaratnam, L. A., \& Doerfel, M. L. (2005). Intercultural communication competence: Identifying key components from multicultural perspectives. International Journal of Intercultural Relations, 29(2), 137-163. https://oi.org/10.1016/j.ijintrel.2004.04.001

Avgousti, M. I. (2018). Intercultural communicative competence and online exchanges: A systematic review. Computer Assisted Language Learning, 31(8), 819-853. https://doi.org/10.1080/09588221.2018.1455713

Avram, M., Micallef, N., Patil, S., \& Menczer, F. (2020). Exposure to social engagement metrics increases vulnerability to misinformation. Technical Report 2005.04682, arXiv, 2020. Bloomington, IN: Indiana University Observatory on Social Media.

Beckett, G. H., \& Slater, T. (2018). Project-based learning and technology. In J. I. Liontas (Ed.), The TESOL encyclopedia of English language teaching (pp. 1-7). Hoboken, NJ: Wiley-Blackwell.

Beckett, G. H., Slater, T., \& Mohan, B. A. (2020). Philosophical foundation, theoretical approaches and gaps in the literature. In G. H. Beckett \& T. Slater (Eds.), Global perspectives on project-based language learning, teaching and assessment. Key approaches, technology tools and frameworks (pp. 3-22). New York/London, UK: Routledge.

Bejarano Sánchez, G., \& Giménez Manrique, G. (2018). What makes our schools unique? A telecollaborative experience from the perspective of two 'new-comers'. In M. Dooly \& R. O'Dowd (Eds.), In this together: Teachers' experiences with transnational, telecollaborative language learning projects (pp. 145-181). New York, NY/Bern, Switzerland: Peter Lang.

Belz, J. A. (2003). From the Special Issue Editor. Language Learning \& Technology, 7(2), 2-5. http://lt.msu.edu/vol7num2/ speced.html.

Bennett, M. J. (1993). Towards a developmental model of intercultural sensitivity. In R. M. Paige (Ed.), Education for the intercultural experience (pp. 21-71). Yarmouth, ME: Intercultural Press.

Bonet Pueyo, A. (2018). Making a difference: Reflecting on a telecollaborative project aimed at social change. In M. Dooly \& R. O’Dowd (Eds.), In this together: Teachers' experiences with transnational, telecollaborative language learning projects (pp. 123-144). New York, NY/Bern, Switzerland: Peter Lang.

Bower, J., \& Kawaguchi, S. (2011). Negotiation of meaning and corrective feedback in Japanese/English eTandem. Language Learning \& Technology, 15(1), 41-71. https://www.lltjournal.org/item/2723. 
Brammerts, H. (1996). Language learning in tandem using the internet. In M. Warschauer (Ed.), Telecollaboration in foreign language learning (pp. 121-130). Honolulu, HI: University of Hawaii Press.

Brown, H. D. (2007). Teaching by principles: An interactive approach to language pedagogy (3rd ed.). New York, NY: Pearson Education.

Bruun, S. (2018). Global goals: A virtual project with students from Sweden and Tanzania. In M. Dooly \& R. O’Dowd (Eds.), In this together: Teachers' experiences with transnational, telecollaborative language learning projects (pp. 199-215). New York, NY/Bern, Switzerland: Peter Lang.

Bueno-Alastuey, M. C., \& Kleban, M. (2016). Matching linguistic and pedagogical objectives in a telecollaboration project: A case study. Computer Assisted Language Learning, 29(1), 148-166. https://doi.org/10.1080/09588221.2014.904360

Byram, M. (1997). Teaching and assessing intercultural communicative competence. Bristol, UK: Multilingual Matters.

Cappellini, M. (2019). A proposal to study the links between the sociocultural and the linguistic dimensions of eTandem interactions. In A. Turula, M. Kurek, \& T. Lewis (Eds.), Telecollaboration and virtual exchange across disciplines: in service of social inclusion and global citizenship (pp. 99-104). Research-publishing.net. https://doi.org/10.14705/rpnet.2019.35.945

Cappellini, M., Lewis, T., \& Rivens Mompean, A. (Eds.). (2017). Learner autonomy and web 2.0. Sheffield: Equinox.

Cedefop. (2017). CEDEFOP opinion survey on vocational education and training in Europe. Thessaloniki, Greece: European Centre for Development of Vocational Training.

Chun, D. M. (2015). Language and culture learning in higher education via telecollaboration. Pedagogies: An International Journal, 10(1), 5-21. https://doi.org/10.1080/1554480X.2014.999775

Çiftçi, Y. E., \& Savaş, P. (2018). The role of telecollaboration in language and intercultural learning: A synthesis of studies published between 2010 and 2015. ReCALL, 30(3), 278-298. doi:10.1017/S0958344017000313

Council of Europe (2018). Common European framework of reference for languages: Learning, teaching and assessment. https: www.coe.int/lang-cefr.

Cunningham, D. J., \& Vyatkina, N. (2012). Telecollaboration for professional purposes: Towards developing a formal register in the foreign language classroom. Canadian Modern Language Review/La Revue Canadienne des Langues Vivantes, 68(4), 422-450. https://doi.org/10.3138/cmlr.1279

Cunningham, J., \& Ryshina-Pankova, M. (2020). What's with the attitude? Exploring attitudinal resources in telecollaboration for teacher education. In A. Oskoz \& M. Vinagre (Eds.), Understanding attitude in intercultural virtual communication. CALICO special volume: Advances in CALL research and practice (pp. 145-165). Sheffield, UK: Equinox.

Cunningham, J. D., \& Akiyama, Y. (2018). Synthesizing the practice of SCMC-based telecollaboration: A scoping review. CALICO Journal, 35(1), 49-76. https://doi.org/10.1558/cj.33156

Dervin, F., \& Gross, Z. (2016). Introduction: Towards the simultaneity of intercultural competence. In F. Dervin \& Z. Gross (Eds.), Intercultural competence in education. Alternative approaches for different times (pp. 1-10). London, UK: Palgrave Macmillan.

De Vellis, R. F. (2003). Scale development: Theory and applications (2nd ed., vol. 26). Thousand Oaks, CA: SAGE.

Dooly, M. (2010). The teacher 2.0. In S. Guth \& F. Helm (Eds.), Telecollaboration 2.0. Language, literacies and intercultural learning in the 21st century (pp. 277-303). New York, NY/Bern, Switzerland: Peter Lang.

Dooly, M. (2015). Networked classrooms and networked minds: Language teaching in a brave new world. In C. J. Jenks \& P. Seedhouse (Eds.), International perspectives on the ELT classroom (pp. 84-109). Houndsmills, Basingstoke, UK/ New York, USA: Palgrave MacMillan.

Dooly, M. (2016). 'Please remove your avatar from my personal space': Competences of the telecollaboratively efficient person. In T. Lewis \& R. O’Dowd (Eds.), Online intercultural exchange: Policy, pedagogy, practice (pp. 192-208). New York, NY/London, UK: Routledge.

Dooly, M. (2017). Telecollaboration. In C. Chapelle \& S. Sauro (Eds.), The handbook of technology in second language teaching and learning (pp. 169-183). Hoboken, NJ: Wiley-Blackwell.

Dooly, M., \& Masats, D. (2020). 'What do you zinc about the project?': Examples of technology-enhanced project-based language learning. In G. Beckett \& T. Slater (Eds.), Global perspectives on project-based language learning, teaching, and assessment: Key approaches, technology tools, and frameworks (pp. 126-145). New York, UK/Abingdon, UK: Routledge.

Dooly, M., \& O’Dowd, R. (2012). Researching online interaction and exchange in foreign language education: Introduction to the volume. In M. Dooly \& R. O'Dowd (Eds.), Researching online foreign language interaction and exchange. Theories, methods and challenges (pp. 11-41). New York, NY/Bern, Switzerland: Peter Lang.

Dooly, M., \& O’Dowd, R. (2018). Telecollaboration in the foreign language classroom: A review of its origins and its application to language teaching practices. In M. Dooly \& R. O’Dowd (Eds.), In this together: Teachers' experiences with transnational, telecollaborative language learning projects (pp. 11-34). New York, NY/Bern, Switzerland: Peter Lang.

Ellis, R. (2015). Understanding second language acquisition. Oxford, UK: Oxford University Press.

Evaluate Group. (2019). Evaluating the impact of virtual exchange on initial teacher education: A European policy experiment. Dublin: Research-publishing.net. https://doi.org/10.14705/rpnet.2019.29.9782490057337

Flowers, S., Kelsen, B., \& Cvitkovic, B. (2019). Learner autonomy versus guided reflection: How different methodologies affect intercultural development in online intercultural exchange. ReCALL, 31(3), 221-237. https://doi.org/10.1017/s0958344019000016

Fuchs, C., Snyder, B., Tung, B., \& Han, Y. J. (2017). The multiple roles of the task design mediator in telecollaboration. ReCALL, 29(3), 239-256. https://doi.org/10.1017/s0958344017000088 
Furstenberg, G. (2010). Making culture the core of the language class: Can it be done? Modern Language Journal, 94(2), 329332. https://doi.org/10.1111/j.1540-4781.2010.01027.x

García-Martínez, A., \& Gracia-Téllez, M. (2018). A telecollaborative science project: Searching for new ways to make language learning authentic. In M. Dooly \& R. O’Dowd (Eds.), In this together: Teachers' experiences with transnational, telecollaborative language learning projects (pp. 35-63). New York, NY/Bern, Switzerland: Peter Lang.

Gardner, R. C., \& Lambert, W. E. (1972). Attitudes and motivation in second language learning. Rowley, MA: Newbury House.

Godwin-Jones, R. (2019). Telecollaboration as an approach to developing intercultural communication competence. Language Learning \& Technology, 23(3), 8-28. http://hdl.handle.net/10125/44691.

Godwin-Jones, R. (2020). Building the porous classroom: An expanded model for blended language learning. Language Learning \& Technology, 24(3), 1-18. http://hdl.handle.net/10125/44731.

Golubeva, I., \& Guntersdorfer, I. (2020). Addressing empathy in intercultural virtual exchange: a preliminary framework. In M. Hauck \& A. Müller-Hartmann (Eds.), Virtual exchange and 21st century teacher education: Short papers from the 2019 EVALUATE conference (pp. 117-126). Dublin, Republic of Ireland: Research-publishing.net. https://doi.org/10.14705/ rpnet.2020.46.1137

González-Lloret, M., \& Ortega, L. (2014). Towards technology-mediated TBLT: An introduction. In M. González-Lloret \& L. Ortega (Eds.), Technology-mediated TBLT: Researching technology and tasks (pp. 1-22). Amsterdam, the Netherlands: John Benjamins Publishing Company.

Habermas, J. (1962/2011). The structural transformation of the public sphere. An inquiry into a category of bourgeois society. (T. Burger \& F. Lawrence, tr.). Cambridge, UK: Polity Press.

Hauck, M., Müller-Hartmann, A., Rienties, B., \& Rogaten, J. (2020). Approaches to researching digital-pedagogical competence development in VE-based teacher education. Journal of Virtual Exchange, 3(SI), 5-35. https://doi.org/10.21827/jve.3. 36082

Helm, F. (2013). A dialogic model for telecollaboration. Bellaterra Journal of Teaching and Learning Language and Literature, 6(2), 28-48. https://doi.org/10.5565/rev/jtl3.522

Helm, F. (2016). Facilitated dialogue in online intercultural exchange. In R. O’Dowd \& T. Lewis (Eds.), Online intercultural exchange: Policy, pedagogy, practice (pp. 150-172). New York, NY: Routledge.

Helm, F., \& Baroni, A. (2020). Researching emotions and attitude through student teachers' reflections on virtual exchange. In A. Oskoz \& M. Vinagre (Eds.), Understanding attitude in intercultural virtual communication. CALICO special volume: Advances in CALL research and practice (pp. 166-195). Sheffield, UK: Equinox.

Hernández-Gantes, V. M., \& Blank, W. (2009). Teaching English language learners in career and technical education programs. Abingdon, UK: Routledge.

Ingelsson, J., \& Linder, A. (2018). Intercultural meetings in a Swedish - Kiwi e-mail exchange: Lessons learnt. In M. Dooly \& R. O'Dowd (Eds.), In this together: Teachers' experiences with transnational, telecollaborative language learning projects (pp. 183-197). New York, NY/Bern, Switzerland: Peter Lang.

Isaksen, S. B. (2018). Teaching and learning English in vocational education programmes in a Norwegian upper secondary school. Some vocational teachers', English teachers' and specialized workers' evaluation of teaching and learning in the school subject English (Master's dissertation). The Artic University of Norway.

Johnson, L. C. (1996). The keypal connection. In M. Warschauer (Ed.), Telecollaboration in foreign language learning (pp. 131-142). Honolulu, HI: University of Hawaii Press.

Kern, R. (1996). Computer-mediated communication: Using e-mail exchanges to explore personal histories in two cultures. In M. Warschauer (Ed.), Telecollaboration in foreign language learning (pp. 105-120). Honolulu, HI: University of Hawaii Press.

Kinginger, C. (1998). Videoconferencing as access to spoken French. Modern Language Journal, 82(49), 502-513. doi:10.1111/j.1540-4781.1998.tb05537.x

Kinginger, C., Gourvès-Hayward, A., \& Simpson, V. (1999). A telecollaborative course on French-American intercultural communication. French Review, 72(5), 853-866. http://www.jstor.org/stable/398359.

Kramsch, C. (2013). Language and culture. In J. Simpson (Ed.), The Routledge handbook of applied linguistics (pp. 305-317). London, UK/New York, NY: Routledge.

Kramsch, C. (2014). Teaching foreign languages in an era of globalization. Introduction. Modern Language Journal, 98(1), 296-311. https://doi.org/10.1111/j.1540-4781.2014.12057.x

$\mathrm{Ku}, \mathrm{A}$. (2000). Revisiting the notion of 'public' in Habermas's theory. Toward a theory of politics of public credibility. Sociological Theory, 18(2), 216-240. Retrieved December 4, 2020, from http://www.jstor.org/stable/223313.

Kumaravadivelu, B. (2006). Understanding language teaching. From method to postmethod. Mahwah, NJ: Lawrence Erlbaum Associates.

Kumaravadivelu, B. (2008). Cultural globalization and language education. New Haven, CT: Yale University Press.

Kurek, M., \& Müller-Hartmann, A. (2017). Task design for telecollaborative exchanges: In search of new criteria. System, 64, 7-20. https://doi.org/10.1016/j.system.2016.12.004

Lamy, M.-N., \& Goodfellow, R. (2010). Telecollaboration and learning 2.0. In S. Guth \& F. Helm (Eds.), Telecollaboration 2.0: language, literacies and intercultural learning in the 21st century (pp. 107-138). New York, NY/Bern, Switzerland: Peter Lang.

Lederach, J. P. (1995). Preparing for peace. New York, NY: Syracuse University Press. 
Lewis, T., \& O’Dowd, R. (2016). Online intercultural exchange and foreign language learning: A systematic review. In R. O’Dowd \& T. Lewis (Eds.), Online intercultural exchange (pp. 35-80). London, UK: Routledge.

Li, L. (2020). Promoting interpersonal and intercultural communication with flipgrid: Design, implementation and outcomes. In M. Kruk \& M. Peterson (Eds.), New technological applications for foreign and second language learning and teaching (pp. 261-281). Hershey, PA: IGI Global.

Liang, J., Xie, F., \& Gao, M. (2020). Beyond exams: Research-based dynamic, technology-mediated, project-based framework for meaningful language learning in secondary EFL setting in China. In G. H. Beckett \& T. Slater (Eds.), Global perspectives on project-based language learning, teaching and assessment. Key approaches, technology tools, and frameworks (pp. 263 282). New York, NY/Abingdon, UK: Routledge.

Little, D. (2001). Learner autonomy and the challenge of tandem language learning via the Internet. In A. Chambers \& G. Davies (Eds.), ICT and language learning: A European perspective (pp. 29-38). Lisse, the Netherlands: Swets \& Zeitlinger.

Little, D., \& Brammerts, H. (1996). A guide to language learning in tandem via the Internet. CLCS Occasional Paper 46. Dublin, Republic of Ireland: Trinity College, Centre for Language and Communication Studies.

Loranc-Paszylk, B. (2016). Incorporating cross-cultural videoconferencing to enhance Content and Language Integrated Learning (CLIL) at the tertiary level. In S. Jager, M. Kurek, \& B. O’Rourke (Eds.), New directions in telecollaborative research and practice: Selected papers from the second conference on telecollaboration in higher education (pp. 131-138). Dublin/Vouillans: Research-publishing.net.

Mahbub, M. (2019). English teaching in vocational high school: A need analysis. JEELS (Journal of English Education and Linguistics Studies, 5(2), 229-258. doi:10.30762/jeels.v5i2.835

McConachy, T., \& Liddicoat, A. J. (2016). Meta-pragmatic awareness and intercultural competence: The role of reflection and interpretation in intercultural mediation. In F. Dervin \& Z. Gross (Eds.), Intercultural competence in education. Alternative approaches for different times (pp. 13-39). London, UK: Palgrave Macmillan.

Merino, M., \& Tileaga, C. (2011). The construction of ethnic minority identity: A discursive psychological approach to ethnic self-definition in action. Discourse \& Society, 22(1), 86-101. doi:10.1177/0957926510382834

Morcilo Salas, A. (2018). Are we really that different? A telecollaborative project between refugee students from Myanmar and a primary school in Sabadell (Spain). In M. Dooly \& R. O'Dowd (Eds.), In this together: Teachers' experiences with transnational, telecollaborative language learning projects (pp. 65-92). New York, NY/Bern, Switzerland: Peter Lang.

Müller-Hartmann, A. (2006). Learning how to teach intercultural communicative competence via telecollaboration: A model for language teacher education. In J. Belz \& S. L. Thorne (Eds.), Internet-mediated intercultural foreign language education (pp. 63-84). Boston, MA: Heinle \& Heinle.

O'Dowd, R. (2015). The competences of the telecollaborative teacher. Language Learning Journal, 43(2), 194-207. https://doi. org/10.1080/09571736.2013.853374

O'Dowd, R. (2018a). From telecollaboration to virtual exchange: State-of-the-art and the role of UNICollaboration in moving forward. Journal of Virtual Exchange, 1, 1-23. Research-publishing.net. https://doi.org/10.14705/rpnet.2018.jve.1

O'Dowd, R. (2018b). Innovations and challenges in using online communication technologies in CLIL. Theory Into Practice, 57(39), 232-240. https://doi.org/10.1080/00405841.2018.1484039

O'Dowd, R., \& Dooly, M. (2020). Intercultural communicative competence through telecollaboration and virtual exchange. In J. Jackson (Ed.), The Routledge handbook of language and intercultural communication (2nd ed., pp. 361-375). Abingdon, UK: Routledge.

O’Dowd, R., Sauro, S., \& Spector-Cohen, E. (2019). The role of pedagogical mentoring in virtual exchange. Tesol Quarterly, 54 (1), 146-172. https://doi.org/10.1002/tesq.543

Ortega, L. (2017). New CALL-SLA research interfaces for the 21st century: Towards equitable multilingualism. CALICO Journal, 34(3), 285-316. https://doi.org/10.1558/cj.33855

Pérez, I., \& Vinagre, M. (2007). How can on-line exchanges be used with young learners. In R. O'Dowd (Ed.), On-line intercultural exchange: An introduction for foreign language teachers (pp. 193-212). Bristol, UK: Multilingual Matters.

Phipps, A., \& Levine, G. S. (2010). What is language pedagogy for? In G. Levine \& A. Phipps (Eds.), Critical and intercultural theory and language pedagogy (pp. 1-14). Boston, MA: Cengage Learning.

Poedjiastutie, D., \& Oliver, R. (2017). Exploring students' learning needs: Expectation and challenges. English Language Teaching, 10(10), 124-133. https://doi.org/10.5539/elt.v10n10p124

Pol, L. (2013). Telecollaboration in secondary education: An added value? (Master's dissertation). Utrecht University.

Risager, K. (2007). Language and culture pedagogy: From a national to a transnational paradigm. Buffalo, NY: Multilingual Matters.

Sauro, S. (2014). SCMC for SLA: A research synthesis. Calico Journal, 28(2), 369-391. https://doi.org/10.1558/cj.33156

Smit, U., \& Dafouz, E. (2012). Integrating content and language in higher education. An introduction to English-medium policies, conceptual issues and research practices across Europe. AILA Review (SI), 25(1), 1-12. doi:10.1075/aila.25.01sm

Spitzberg, B. H., \& Changnon, G. (2009). Conceptualizing intercultural competence. In D. K. Deardorff (Ed.), The SAGE handbook of intercultural competence (pp. 2-52). Thousand Oaks, CA: SAGE.

Starke-Meyerring, D., \& Wilson, M. (2008). Designing globally networked learning environments: Visionary partnerships, policies, and pedagogies. Rotterdam, the Netherlands: Sense Publishers. 
Telles, J. A. (2009). Teletandem: Um contexto virtual, autônomo e colaborativo para aprendizagem de línguas estrangeiras no século XXI. Campinas, Sao Paulo: Pontes Editores.

Thomas, M., \& Yamazaki, K. (2021). Project-based language learning and CALL. From virtual exchange to social justice. Sheffield, UK: Equinox.

Thornbury, S. (2013). Language teaching methodology. In J. Simpson (Ed.), The Routledge handbook of applied linguistics (pp. 185-199). London, UK/New York, NY: Routledge.

Train, R. (2006). A critical look at technologies and ideologies in internet-mediated intercultural foreign language education. In J. A. Belz \& S. L. Thorne (Eds.), Internet-mediated intercultural foreign language education (pp. 247-284). Boston, MA: Thomson Heinle.

Vinagre, M. (2016a). Developing key competences for life-long learning through virtual collaboration: Teaching ICT in English as a medium of instruction. In C. Wang \& L. Winstead (Eds.), Handbook of research on foreign language education in the digital age (pp. 170-187). Hershey, PA: IGI Global. doi:10.4018/978-1-5225-0177-0.ch008

Vinagre, M. (2016b). Promoting intercultural competence in culture and language studies: Outcomes of an international collaborative project. In E. Martín-Monje, I. Elorza, \& B. García Riaza (Eds.), Technological advances in specialized linguistic domains: Practical applications and mobility (pp. 23-35). London, UK: Routledge.

Vinagre, M. (2017). Developing teachers' telecollaborative competences in online experiential learning. System, 64, $34-45$. https://doi.org/10.1016/j.system.2016.12.002

Vinagre, M., \& Corral, A. (2018). Evaluative language for rapport building in virtual collaboration: An analysis of Appraisal in computer-mediated interaction. Journal of Language and Intercultural Communication, 18(3), 335-350. doi:10.1080/ 14708477.2017.1378227

Vinagre, M., \& Corral, A. (2019). Tracing the development of intercultural competence in telecollaborative interaction: An analysis of evaluative language in eTandem exchanges. In C. Tardieu \& C. Horgues (Eds.), Redefining tandem language and culture learning in higher education (pp. 95-112). London, UK: Routledge.

Vinagre, M., \& Muñoz, B. (2011). Computer-mediated corrective feedback and language accuracy in telecollaborative exchanges. Language Learning \& Technology, 15(1), 72-103. http://ltt.msu.edu/issues/february2011/vinagremunoz. pdf.doi:10125/44238

Vinagre, M., \& Oskoz, A. (2020). Exploring attitude in bilingual virtual exchanges: A linguistic perspective. In A. Oskoz \& M. Vinagre (Eds.), Understanding attitude in intercultural virtual communication. CALICO special volume: Advances in CALL research and practice (pp. 64-92). Sheffield, UK: Equinox.

Ware, P., \& O’Dowd, R. (2008). Peer feedback on language form in telecollaboration. Language Learning \& Technology, 12(1), 43-63. http://lit.msu.edu/vol12num1/wareodowd/

Warschauer, M. (1995). Virtual connections: Online activities and projects for networking language learners. Honolulu, HI: University of Hawaii Second Language Teaching and Curriculum Center.

Whyte, S., \& Gijsen, L. (2016). Telecollaboration in secondary EFL: A blended teacher education course. In S. Jager, M. Kurek, \& B. O'Rourke (Eds.), New directions in telecollaborative research and practice: selected papers from the second conference on telecollaboration in higher education (pp. 163-170). Dublin, Republic of Ireland: Research-publishing.net. https://doi.org/10.14705/rpnet.2016.telecollab2016.503

Melinda Dooly holds a Serra Húnter fellowship as researcher and senior lecturer in the Department of Language \& Literature Education and Social Science Education at the Universitat Autònoma de Barcelona. She teaches English as a Foreign Language Methodology (TEFL) and research methods courses, focusing on telecollaboration and technology-enhanced teaching at both undergraduate and graduate levels. Her principal research addresses technology-enhanced project-based language learning, intercultural communication and 21 st century competences in teacher education. She has published widely in international journals and authored chapters and books in this area of study and is co-editor of the book series Telecollaboration in Education (Peter Lang). She is lead researcher of GREIP: Grup de Recerca en Ensenyament i Interacció Plurilingües (Research Centre for Teaching \& Plurilingual Interaction).

Margarita Vinagre is an Associate Professor at Autónoma University of Madrid where she teaches Educational Technologies and English Language and Linguistics. Her main research interests are the integration of technologies in the foreign language classroom, computer-mediated communication, and the implementation of virtual exchange for the development of linguistic and generic competences. She has published widely on these topics and her publications have appeared in specialized journals including Language Learning \& Technology, CALL, System, The British Journal of Educational Technology, CALICO, and The Journal of Language and Intercultural Communication and Computers \& Education. She is a member of the Editorial Boards of the Eurocall Review and CALICO. Currently, she is the principal investigator of the VELCOME project on the integration of virtual exchange for key competence development in higher education, with 20 participating researchers from five countries.

Cite this article: Dooly, M., \& Vinagre, M. (2022). Research into practice: Virtual exchange in language teaching and learning. Language Teaching, 55(3), 392-406. https://doi.org/10.1017/S0261444821000069 